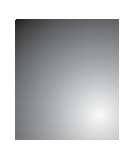

\title{
Empreendedorismo Feminino: DIFICULDADES RELATADAS EM HISTÓRIAS DE VIDA
}

Female Entrepreneurship: difficulties reported in life stories

\section{Graziela Dias Alperstedt}

Professora e pesquisadora da ESAG/Universidade do Estado de Santa Catarina. Florianópolis, SC. Brasil. E-mail: gradial@gmail.com

\section{Juliane Borges Ferreira}

Professora e Consultora da Advanced Design in Management S.A. Florianópolis, SC. Brasil. E-mail: julybferreira@gmail.com

\section{Maurício Custódio Serafim}

Coordenador do Mestrado Acadêmico em Administração, professor e pesquisador da ESAG/Universidade do Estado de Santa Catarina. Florianópolis, SC. Brasil. E-mail: serafim.esag@gmail.com

\section{Resumo}

O objetivo deste artigo é analisar os problemas encontrados ao longo do processo empreendedor, a partir das histórias de vida das participantes do Prêmio SEBRAE Mulher de Negócios em Santa Catarina. Para tanto, analisou-se as histórias empreendedoras das 86 participantes do Prêmio edição de 2010. Esses relatos foram analisados de forma interpretativa. Destaca-se, como dificuldades encontradas no processo empreendedor, a percepção da falta de confiança nelas depositada e o conflito pessoal, familiar e empresarial, sendo estas últimas dimensões conflitantes na vida dessas mulheres, pois concorrem por sua atenção. São apontados, ainda, aspectos relativos à gerência do negócio, sendo as questões financeiras e as de mercado as mais graves.

Palavras-chave: Mulher. Empreendedorismo. História de Vida. Dificuldades.

\section{Abstract}

The objective of this paper is to analyze the problems detected along the entrepreneurial process, from the life stories of the SEBRAE Award Business woman participants in Santa Catarina state. Therefore, were analyzed the stories of 86 entrepreneurs participating of Prize 2010 edition. These reports were analyzed by interpretation. How to difficulties encountered in the entrepreneurial process are the perceived lack of trust placed in them, as well as the personal, family and business conflict, being the latters conflicting dimensions in the lives of these women as competing for their attention. Are still pointed aspects of business management, and financial issues and market the most serious.

Keywords: Women. Entrepreneurship. Life History. Difficulties. 


\section{INTRODUÇÃO}

As mulheres vêm se destacando cada vez mais no mercado de trabalho. O que suscita um crescente interesse, tanto por parte do setor público, como por parte das instituições acadêmicas sobre o fenômeno do empreendedorismo feminino. (NOGUERA; ALVAREZ; URBANO, 2013)

No Brasil, a pesquisa GEM (2012) aponta que o número de mulheres à frente de negócios estabelecidos foi de $44 \%$ e de negócios iniciais foi de $49,6 \%$. Outro destaque da pesquisa GEM (2012) revela que a maioria dessas empreendedoras é guiada por uma oportunidade de mercado $(73,9 \%)$ e não por necessidade, como vinha acontecendo com as mulheres de uma forma geral. Ainda, pode-se ressaltar que o empreendedorismo feminino por oportunidade foi maior que o masculino na mesma condição. (GEM, 2012)

Em 2004, com o intuito de valorizar a trajetória das mulheres empreendedoras brasileiras o SEBRAE criou o Prêmio SEBRAE Mulher de Negócios (PSMN). Esse prêmio é realizado em etapas estaduais, regionais $e$, por fim, nacional. A escolha do Estado de Santa Catarina como foco desta pesquisa se explica em função dos dados, como os da pesquisa do IBGE (2010), que apontam que empresas criadas por mulheres nesse Estado apresentam taxa de sobrevivência de $82,2 \%$, estando acima da média nacional, que é de $78,1 \%$, acima de estados com forte tradição econômica como São Paulo (78,7\%), Minas Gerais $(79,6 \%)$ e Rio de Janeiro (80,5\%). No comparativo com outras regiões do país (GEM, 2012), a Região Sul, juntamente com o Nordeste obteve o maior índice de empreendedorismo feminino $(51,8 \%)$.

Esse trabalho não se propõe a comparar homens e mulheres, mas admite que no contexto social e familiar, os recursos de tempo e energia necessária para a reprodução, para desempenhar o papel de mãe e os trabalhos domésticos, muitas vezes entram em conflito com as demandas de desenvolvimento de uma carreira empreendedora eficaz (MARLOW, 1997). O sucesso profissional geralmente dita longas horas de trabalho, com uma demonstração individual de ambição pessoal e comprometimento com a empresa (DAILY; CERTO; DALTON, 1999). Assim, pesquisas demonstram que a vida familiar tem um impacto dramático sobre as mulheres empreendedoras (WINN, 2004). Além da relação trabalho-família, outros problemas surgem no processo empreendedor feminino. Muitos desses problemas são inerentes ao empreendedorismo em si, outros, porém, alinham-se ao caráter feminino do empreendimento.

Tendo em vista o papel da mulher como empreendedora e sua inserção do contexto social em que atua, esse trabalho objetiva analisar os problemas encontrados ao longo do processo empreendedor nas histórias de vida das participantes do Prêmio SEBRAE Mulher de Negócios. O trabalho segue a indicação de Gartner e Birley (2002) para os quais questões substantivas em empreendedorismo raramente são abordadas, além de que muitas das questões importantes dentro do campo do empreendedorismo só podem ser estudadas por meio de métodos e abordagens qualitativas.

\section{Empreendedorismo Feminino e suas Dificuldades}

A análise da evolução do número de mulheres empreendendo, revela que este fato vem sendo construído ao longo dos anos. Nos últimos dez anos, a quantidade de homens e mulheres que abriram novas empresas no país se manteve estável, e o número de homens é pouco maior que o de mulheres ( $56 \%$ de homens contra $44 \%$ de mulheres) segundo relatório GEM (2012), exceto em 2007 e 2009, quando as mulheres ganharam maior destaque. (GEM, 2010)

Analisando o empreendedorismo em diferentes localidades, constata-se que a proporção entre homens e mulheres varia de país para país. Porém, de maneira geral, o número de mulheres empreendedoras ainda é inferior ao número de homens (GEM, 2012), fato que pode ser justificado pela estrutura social, cultura, costumes e estrutura tecnológica de cada país.

O debate sobre o empreendedorismo feminino, entretanto, não suscita apenas o ingresso da mulher no mercado de trabalho para complementar a renda da família. Trata-se de alteração social de grandes proporções, provocando não somente transformações nas expectativas de vida pessoal, como também nas relações familiares e nas demandas por serviços públicos, entre outros fatores (GOMES, 2004). Naturalmente, o processo empreendedor já é dotado de dificuldades e 
entraves que se colocam ao empreendedor. As mulheres, por conta de sua construção histórica atrelada ao gênero feminino, enfrentam ainda dificuldades extras quando empreendem.

Mcgowan, Redeker, Cooper e Greenan (2012) constataram em sua pesquisa que, para muitas mulheres, o prazer experimentado no gerenciamento de sua própria empresa resultante da maior liberdade e flexibilidade é temperado por descontentamento, em função das demandas de tempo entre as necessidades de equilibrar as exigências do negócio $e$ os interesses dos filhos e outros dependentes. Assim, a realidade da experiência empreendedora feminina muitas vezes apresenta aspectos negativos e uma fonte de tensão real. As experiências negativas surgem a partir de questões como os compromissos conflitantes, sentimentos de culpa e as tensões decorrentes de seus pontos de vista e dos outros sobre o papel tradicional das mulheres na sociedade, especialmente seu papel de mãe e cuidadora principal. Outros aspectos são decorrentes de questões de saúde pessoal, bem-estar emocional, níveis de energia, sentimentos de isolamento e estresse dentro das relações pessoais. Do ponto de vista profissional, as mulheres também apresentam dificuldades decorrentes de sua falta de experiência como empreendedoras, medo do risco financeiro e da dívida, falta de modelos e o baixo nível de assistência.

É possível elencar as dificuldades listadas na literatura brasileira e estrangeira acerca do empreendedorismo feminino. Sem considerar a ordem de importância dessas dificuldades, a primeira delas relaciona-se à inserção da mulher em alguns setores de atuação tidos como carreiras masculinas. Um exemplo disso é o setor de tecnologia da informação composto por maioria de homens, prevalecendo uma baixa representatividade de empresas constituídas por mulheres nas incubadoras tecnológicas (BOTELHO et al., 2008). Nessa perspectiva, Noguera, Alvarez e Urbano (2013) destacam o medo do fracasso e a percepção de capacidades como os fatores socioculturais que mais influenciam no empreendedorismo feminino. Porto (2002) também verificou resistência e discriminação em alguns setores profissionais, como medicina, farmácia e advocacia. Como resultado dessa atitude, muitas mulheres acabam por tentar imitar os homens na forma de se vestir ou agir. As empreendedoras estudadas por Porto (2002) também sofreram o peso da reação dos maridos e homens próximos, pelo ciúme, inveja e rivalidade.

Outro conflito vivido específico da mulher empreendedora, conforme destacado por Mcgowan, Redeker, Cooper e Greenan (2012), é de ordem pessoal. O conflito trabalho-família envolve o embate entre as atividades tradicionalmente exercidas pela mulher na sociedade, tais como o trabalho doméstico e o cuidado dos filhos, e o empreendimento. Sobre essa questão, o estudo de Buttner e Moore (1997) destaca a influência da família na decisão de empreender como um dos fatores mais citados, sofrendo, muitas vezes, pressão tanto do marido quanto dos filhos (STROBINO, 2009). Nesse sentido, Porto (2002) aborda a culpa sentida pelas mulheres empresárias, por deixarem os filhos aos cuidados de outros, na buscar pela realização profissional.

A figura do marido também exerce um papel crucial na vida das mulheres empreendedoras. Embora esse laço seja forte e a divergência de pensamento e opinião possa limitar essa relação, é uma fonte de apoio emocional de destaque no fortalecimento do ato de empreender pela mulher (BRUCE, 1998). A relação estabelecida entre a mulher empreendedora e o marido tanto pode auxiliar no processo empreendedor, como pode se revelar um entrave. Muitas mulheres recorrem ao marido como fonte de recursos, apoiando e financiando suas ideias. A figura masculina também é comumente citada como conselheira na tomada de decisão.

Os conflitos trabalho-família também foram investigados por Strobino (2009). O estudo baseou-se em três dimensões: tempo dispensado ao trabalho, muitas vezes maior do que o vivido quando atuavam como funcionárias de empresas; tensão ocasionada pelos problemas gerados pela dedicação ao negócio; $e$ comportamento, que é resultante da carga elevada de trabalho e responsabilidades com a família. A autora aponta que o conflito é mais comumente encontrado em proprietárias de pequenas empresas, cuja fronteira entre o trabalho, vida pessoal e a família não está bem definida. Um fator de destaque que contribui para o aumento das pressões sentidas pelas empreendedoras é a ausência de colaboração por parte dos filhos $e$ do cônjuge. No intuito de alcançar um equilíbrio entre o aspecto profissional e o pessoal, as mulheres empreendedoras buscam o controle das emoções na 
tentativa de evitar discussões, o equilíbrio de horários, o compartilhamento com a família das atividades domésticas, a busca do diálogo e o apoio na família (STROBINO, 2009). Apesar desse conflito, Powell e Eddleston (2013) constataram em estudo com $253 \mathrm{em}$ preendedores de ambos os sexos que o apoio familiar para as mulheres está positivamente relacionado com o sucesso empreendedor ao passo que o estudo não ofereceu suporte para a noção de que empreendedores do sexo masculino se beneficiam destas ligações. Segundo os autores, as mulheres podem experimentar esses benefícios justamente em função de sua relativa falta de acesso a outros recursos, como humano, social e capital financeiro e porque o papel do sexo feminino encoraja-as a buscar a sinergia trabalho-família.

Outra dificuldade, apontada na literatura em relação ao processo empreendedor feminino, diz respeito à desvantagem sentida no tocante às fontes dos recursos. Muitas empreendedoras, na falta de recursos próprios para montar seu próprio negócio, se veem dependentes do aporte de capital pelo marido, o que pode vir acompanhado de cobranças ou do medo do fracasso. Nesse sentido, a captação de recursos no mercado é vista como um processo com diversas barreiras: acesso a recursos financeiros, humanos e de capital social. Lockyer e George (2012) destacam que em seu estudo sobre as barreiras ao empreendedorismo feminino na Inglaterra, o risco financeiro foi um dos principais entraves.

De acordo com Filion, citado no relatório GEM (2010), 25\% das mulheres acreditam que são tratadas de forma diferente pelas instituições financeiras. Frente a isso, a busca de recursos para empreender, no caso das mulheres, ainda configura-se como um entrave no processo. Uma barreira está atrelada às garantias exigidas pelas instituições financeiras, visto que, comumente as mulheres são dependentes de outros, como maridos ou outras figuras masculinas, carecendo do aval destes para viabilizar o financiamento. Tal posição de subjugação confere à mulher uma postura mais conservadora no que concerne ao risco, resultando na baixa proporção de recursos de terceiros na capitalização inicial da empresa. (BARBOSA et al., 2011)

Machado et al. (2003) verificou que a fonte de capital inicial das empresas criadas por mulheres no Brasil, Canadá e França, são os recursos provenientes de economias pessoais, assim como empréstimo de familiares e amigos. Penhor de joias e venda de imóvel também foram fontes encontradas na pesquisa das autoras. Já entre as empreendedoras francesas verificou-se maior proporção de captação de recursos junto a bancos, do tipo hipoteca. Um agravante frente aos entraves encontrados pelas mulheres em captar recursos é o setor de atuação no qual empreendem (JONATHAN, 2003), pois, nos setores que necessitam de inovação intensiva, existe maior dificuldade de recursos para financiar essas atividades.

Porto (2002) destaca, ainda, a existência de uma forte pressão por parte dos maridos no que se refere à provisão do lar, mostrando uma grande resistência nas transformações quanto às tradicionais atribuições femininas e masculinas. Em seu estudo, foi frequente o discurso das mulheres entrevistadas que fingiam ser o marido o principal provedor da família de forma a manter a crença de dependência a eles. Contudo, embora a pesquisa de Porto (2002) evidencie o peso que as mulheres dão ao trabalho, a família ainda aparece como valor de destaque.

\section{Procedimentos Metodológicos}

Considerando as características do objeto de estudo, adotou-se nessa pesquisa uma abordagem qualitativa a partir das histórias de vida de mulheres empreendedoras. Técnicas estatísticas simples também foram utilizadas com o intuito de caracterizar o universo pesquisado. A população abrange as empreendedoras de Santa Catarina. O nível de análise da pesquisa é o individual e o foco restringiu-se às dificuldades encontradas na experiência empreendedora de mulheres a partir do contexto social vivido.

A seleção da amostra foi intencional, ou seja, definida propositadamente, baseando-se na conveniência e acessibilidade do pesquisador aos dados (FLICK, 2009). A amostra compreende o grupo de mulheres participantes do Prêmio SEBRAE Mulher de Negócios de Santa Catarina no ano de 2010, a qual contempla as participantes da modalidade proprietária de micro e pequenas empresas e membros de grupos de produção formais (cooperativas e associações). A amostra definida é composta por uma repetição do sujeito típico, o qual possui as características que o fazem representativo da população, ou seja, todas as 
participantes do prêmio são mulheres, catarinenses e empreendedoras. (RICHARDSON, 1999)

A escolha pela utilização das histórias do Prêmio SEBRAE Mulheres de Negócios se deu em virtude do reconhecimento que a instituição possui e pela tradição do prêmio que ocorre desde 2002, passando por correções e reformulações. Acrescenta-se a isso o trabalho de divulgação feito em todo o país que engrandece o projeto e atinge um alto índice de participação. Zahra e Wright (2011) sugerem que o contexto empreendedor deva ser tratado não como uma variável de controle, mas como parte da história. O contexto, em empreendedorismo é, para os autores, útil para descobrir problemas e questões para serem estudadas, ao invés de ser definido, a priori, ajudando a estabelecer sua relevância teórica e prática. Foi nesse sentido que o objetivo aqui proposto foi descrito. A partir da análise das histórias foi possível perceber as dificuldades empreendedoras como fator de destaque no material analisado.

Conforme destacado na introdução do trabalho, o Estado de Santa Catarina foi escolhido em função de sua relevância em relação à taxa de sobrevivência das empresas empreendidas por mulheres (82\%) segundo dados do IBGE (2010), estando, portanto acima da média nacional $(78,1 \%)$ e de estados como São Paulo (78,7\%), Minas Gerais $(79,6 \%)$ e Rio de Janeiro $(80,5 \%)$.

As empreendedoras pertencem a diferentes regióes do estado e representam realidades distintas. No estudo abrange-se 86 participantes inscritas no prêmio, as quais realizaram inicialmente a inscrição no site do SEBRAE e que, posteriormente, enviaram sua história. $\mathrm{O}$ uso das histórias das empreendedoras como fonte de dados, é possibilitado por uma cláusula no regulamento que permite ao SEBRAE o direito ao uso dos relatos. Ao descrever sua história de vida, as mulheres buscaram reconstruir os passos que deram na caminhada rumo ao esperado sucesso, relembrando os fatos marcantes e suas interpretações sobre as experiências vividas. A coleta de dados ocorreu, portanto, nas histórias de vida autobiografadas das empreendedoras.

A análise dos dados foi conduzida de forma interpretativa e foi aplicada nos textos que descrevem as histórias das empreendedoras catarinenses. A primeira etapa da análise ocorreu a partir da leitura de todas as histórias. Essa etapa foi crucial para obter uma percepção geral e refletir sobre o significado das histórias contadas. Nesta etapa muitas ideias foram sendo anotadas ao longo dos relatos.

Após essa primeira fase, os documentos foram novamente lidos, dessa vez buscando os significados a partir do objetivo proposto, ou seja, desvelar as dificuldades das mulheres em suas experiências empreendedoras, já que este era um fator que chamou a atenção das pesquisadoras na etapa de pré-análise.

As informações foram então tabuladas em planilha Excel. Dessa forma, foi possível agrupar relatos semelhantes segundo essa dimensão definida, proporcionando a correspondência das diferentes percepções acerca do mesmo enfoque, trazendo evidências que corroborariam ou refutariam o quadro teórico no qual a pesquisa se baseou e revelando outras.

$\mathrm{O}$ material foi organizado na sequência que se adotou para a análise de modo a facilitar o processo. Dos relatos foram somente retirados os conteúdos relevantes para o esclarecimento do objetivo do estudo. Releituras foram realizadas com vistas a não deixar que nenhum dado importante se perdesse, prejudicando assim o processo de análise.

Os dados que puderam ser quantificados sofreram análises estatísticas simples, principalmente a distribuição de frequência de respostas, gerando dados percentuais.

Conforme recomenda Flick (2009) a etapa de coleta de dados e análise das 86 histórias de vida das empreendedoras foi interligada, acontecendo entre os meses de setembro de 2011 e fevereiro de 2012.

\section{Resultados}

Quanto ao perfil, pode-se constatar que as mulheres de Santa Catarina pesquisadas e que ingressam no mundo empreendedor são jovens, ou seja, $84 \%$ delas empreenderam com menos de 44 anos. A média de idade na abertura da empresa é de 29 anos. Do total das histórias analisadas, $37 \%$ das mulheres estão na faixa dos 25 aos 34 anos, $21 \%$ até de 24 anos, $26 \%$ entre 35 e 44 anos. Poucas empreenderam após os 45 anos e 7\% de 45 a 54 anos. Do total, sete empreendedoras assumiram empresa familiar.

A grande maioria é casada (58\%) e, dessas, quase todas possuem filhos (52\%). Poucas citam serem 
chefes de família (36\%), outras (17\%) evidenciam a participação de ambos os cônjuges nas despesas familiares.

As empreendedoras cujas histórias foram estudadas preocupam-se com os estudos. Mesmo com as dificuldades para estudar, a maioria possui ensino médio (38\%), ensino superior (34\%) e até especialização (20\%). Aquelas que não concluíram o ensino superior por dificuldades familiares buscaram fazê-lo ao longo da jornada como empreendedoras. Os relatos revelam que a busca de conhecimentos é importante para essas mulheres. São mulheres típicas de famílias de classe média, cuja cultura tradicional é a de estudo e trabalho para melhorar de vida.

As empreendedoras catarinenses possuíam experiência prévia anterior $(71 \%)$ o que impactou na decisão por empreender. A maioria das empresas constituídas pelas mulheres é do setor de comércio $(47 \%)$ e serviços (34\%). Poucas são indústrias (13\%).

A localização das empresas também segue uma distribuição homogenia no estado, com maior concentração na região Norte, seguido do Vale do Itajaí e menor incidência das empresas no extremo oeste e serra catarinense.

Com relação ao tempo de abertura, a maior parte das empresas é jovem e apenas $6 \%$ são empresas de segunda ou terceira geração. O tempo médio de constituição é de 14 anos, fato que se traduz em alta taxa de sobrevivência das empresas.

A grande maioria das empresas possui a menor faixa de tamanho, entre micro e pequena, tendo como base o faturamento abaixo de $\mathrm{R} \$ 240 \mathrm{mil}$ ao ano. No que se refere ao número de empregados, a maior parte possui poucos funcionários e $48 \%$ com até cinco colaboradores.

O empreendedorismo motivado por oportunidade é mais frequente entre as mulheres catarinenses (70\%). Dentre as necessidades que motivam a ação, destacaram-se, sobretudo as necessidades intrínsecas (abordada em $62 \%$ das histórias), necessidades extrínsecas (visto em 16\% dos casos), necessidade de segurança e bem estar da família (verificado em 13\% dos relatos) e a necessidade de autonomia e independência (verificado em $6 \%$ das histórias).

A constituição jurídica adotada pela maior parte das empresas foi a sociedade, conforme se identifica nos relatos. Essa sociedade se deu com marido, pais ou amigos. Porém, algumas sociedades foram desfeitas por problemas nessas relações.

A implementação da empresa também ocorreu de forma diferenciada. No início mais informal, iniciaram na casa da empreendedora ou em local cedido por amigos ou parentes. Os primeiros clientes são familiares e amigos, os funcionários da empresa são os sócios, e os familiares também são chamados a ajudar. Os recursos materiais para a consecução dos negócios são familiares, emprestados ou financiados com fornecedores. O marketing e a propaganda ocorrem por meio da rede informal.

A fonte de capital para o estabelecimento da empresa é, em geral, via recursos próprios (57\%). Das histórias $43 \%$ apontam recursos de terceiros complementando o capital inicial da empresa, sendo recursos advindos de familiares, principalmente dos maridos, amigos, negociação com fornecedores e apenas $8 \%$ de instituições financeiras.

\subsection{Dificuldades Relacionadas ao Fato de Serem Mulheres}

De acordo com os relatos das mulheres cujas histórias foram analisadas, a maior barreira que ultrapassaram diz respeito ao preconceito por serem mulheres e empreenderem em ramos tidos como masculinos o que gerou falta de credibilidade de outras pessoas, corroborando o trabalho de Botelho et al. (2008). Além disso, um agravante maior é o fato de serem jovens, além da necessidade de conciliação de múltiplos papéis.

Das histórias analisadas, cinco mulheres relataram dificuldades por estarem empreendendo em áreas tidas como masculinas. Esses casos mostram que as mulheres demoraram mais tempo para ganhar reconhecimento. Seu histórico como empreendedoras inicia-se, na maioria das vezes, ao assumir empresa familiar, consequência de uma sucessão planejada ou inesperadamente pelo falecimento do patriarca.

[...] sendo a função técnica voltada ao perfil masculino, do dia para noite fui obrigada a me interar dos processos de produção da empresa. [...] Hoje em dia a dificuldade sentida é ainda a discriminação pela parte masculina na questão metalúrgica em fabricação de engrenagens. Atividades que anteriormente só homens eram 
responsáveis e hoje com o advento da mulher frente ao mercado do trabalho, ainda não são totalmente valorizadas (História 73).

[...] meu pai pediu para eu ajudá-lo. Mas ele resolveu abandonar o barco e eu embora não fosse o capitão resolvi ficar, mesmo que correndo o risco de naufragar. [...] ser mulher em um ramo muito masculino, pois nosso principal cliente é o caminhoneiro ou chefe de oficina, e tinha vezes que as pessoas chegavam e diziam: 'eu quero falar com um homem', mas isso até hoje ainda existe (História 83).

Quando o empreendimento se dá com a ajuda do marido, essa dificuldade é amenizada, pois com ele conseguiu conhecer o mercado de atuação da futura empresa. Mas, embora a ajuda do cônjuge a desse mais confiança, ele não fazia parte do dia a dia empresarial:

Não teve um início muito fácil, uma vez que este segmento é dominado por homens, com desconfianças por parte de seus clientes sobre a sua capacidade e competência para serem atendidos adequadamente. Com muito tato $e$ demonstrações de conhecimento, a empresa conseguiu ganhar a credibilidade necessária para crescer no mercado (História 45).

O preconceito sentido pelas mulheres veio tanto na relação com fornecedores como com funcionários. Uma delas assume a empresa do pai após seu falecimento, um negócio voltado ao comércio varejista. Formou-se professora e não tinha experiência na administração da empresa, o que a fez sentir muita dificuldade para estabelecer relação com os antigos funcionários ou novos fornecedores.

A maior dificuldade que tive foi que, frente à morte de meu pai e a minha falta experiência e de conhecimento administrativo, poucas pessoas ofereceram ajuda. Quando eu pedia ajuda a alguém, muitas vezes arranjaram desculpas para não passar as informações que eu precisava. Sofri, e sofro preconceito por ser mulher e por ser tão nova. As pessoas pré julgam a competência pela aparência. Os fornecedores que já me conheciam, de quando meu pai ainda era vivo, mas quando havia a tentativa de abrir um novo fornecedor, geralmente desconfiavam da credibilidade da minha empresa, e na maioria das vezes eles vinham com a frase: Nossa! Mas que novinha pra estar administrando uma empresa! (História 13).
Neste momento da construção aconteceram as primeiras dificuldades, onde foi possível vivenciar como as pessoas que trabalham neste ramo (construção) tem a visão de que mulher não tem capacidade de comandar uma obra. Um outro fator que agravava esta relação era a idade, pois nesta época eu tinha apenas vinte e três anos. (História 44).

Quando precisei de um lugar maior para ampliar as instalações muitos foram os 'nãos' por inúmeros motivos, desde preconceito por ser mulher e muito nova, como não acreditavam que o trabalho iria dar certo (História 50).

Como nos casos acima, algumas mulheres citam que além do preconceito por serem mulheres foram discriminadas por serem jovens. Estes acontecimentos tinham como base uma ideia preconcebida de que a empreendedora não possuía experiência na função $e$ capacidade de realizar a tarefa. Para as mais jovens não era dado credibilidade.

No empreendedorismo as mulheres vêm conquistando seu espaço com crescente participação ao longo dos anos. Em alguns casos, porém, percebe-se o cuidado para ocultar as suas características ou fragilidades femininas, com medo de que isso possa demonstrar que não possuem capacidade para gerir um negócio:

Não posso demonstrar fragilidade" (História 48). "Com nosso trabalho mostramos a nós mulheres que nós somos capazes de realizar nossos sonhos entrando neste mundo onde éramos apenas donas de casa e estamos mudando esse preconceito neste mundo competitivo (História 31).

Quanto aos múltiplos papéis que passaram a ter que conciliar, como mães, esposas e empresárias, apontam os cuidados com os filhos como o de maior peso. Isso se justifica pelos filhos serem ainda muito pequenos, principalmente em fase de amamentação, quando precisavam ir com a mãe para a empresa, ou eram deixados sob os cuidados de parentes.

Sou mãe, esposa, filha, dona de casa e proprietária de uma loja, preciso conciliar tudo isso, para satisfazer a todos na família e na empresa. Sou muito feliz por ter conseguido meu sonho de ter uma empresa própria (História 31).

Controle da produção, compras, cobranças, balanços e ainda cuidava dos meus filhos com 
todo amor e carinho, não me ausentando da função de mãe enquanto trabalhava (História 38).

Eu trazia de manhã a minha filha que nessa época tinha cinco anos. Ela vinha dormindo e eu trazia uma mala de roupas e cobertas, porque aqui na nossa cidade faz muito frio e, além disso, eu fazia almoço na empresa mesmo. Meu Deus como era triste essa fase de tirar ela da caminha e levá-la comigo num lugar que não era nem ao menos limpo para ela brincar. Eu fazia um chá com pão e deixava-a assistindo televisão, era uma cozinha meio 'rústica' podemos chamar assim, nos fundos da empresa e assim que dava uma folguinha corria dar uma olhadinha nela (História 85).

O conflito entre a vida pessoal, familiar (como mãe e esposa) e os afazeres da nova empresa está presente em quase todas as histórias. A preocupação e a culpa que as mães relatam se constituíram em contratempos com os quais tiveram que aprender a lidar e, para isso, contaram com o apoio familiar.

Na busca incessante de atingir minhas metas profissionais tivemos que abrir mão de muitos momentos juntos. Porém olhando para traz, vejo que cada segundo valeu a pena, pois juntos "construímos" a base sólida para poder ajudar as pessoas de uma forma única (História 80).

Ainda é grande o peso que a sociedade dá à mulher como responsável por todos esses cuidados com a casa e os filhos. As mulheres, embora tenham posicionamentos modernos quanto ao papel de ambos os cônjuges, acabaram por internalizar os valores sociais que aprenderam com os pais.

A minha educação sempre foi muita rígida, com pensamento de que mulher não tem que trabalhar, e sim cuidar da casa e dos filhos. [...] no fato do empreendedorismo, não tivemos dificuldades por ser mulher, e colocamos em nossa cabeça determinação, o que realmente nos salvou em momentos complicados foi a nossa força de vontade (História 27).

Porém, essa educação não fez com que as mulheres desistissem de criar suas empresas. Assim, buscaram soluções e conciliaram as dimensões pessoais, familiares e empresariais.

\subsection{Outras Dificuldades no Processo Empreendedor}

As demais dificuldades relatadas pelas mulheres ao longo do processo empreendedor são principalmente acontecimentos de sua vida pessoal que se interpõem aos cuidados com a empresa e também os problemas financeiros e com a gestão do negócio.

Problemas de ordem pessoal são presentes em muitas histórias sendo mais recorrentes os relatos de doença ou falecimento de entes queridos como marido, filhos, pais, irmãos e até mesmo com um dos sócios. Duas empreendedoras tiveram problemas pessoais graves de saúde.

Uma guinada em minha vida ocorreu em 1992 quando meu filho mais novo sofreu um acidente e teve morte cerebral. Foi uma decepção enorme, já que sacrifiquei um pouco da minha presença como mãe para poder dar conforto a eles e uma tragédia dessas transformou totalmente os planos que havia traçado para minha vida (História 38).

[...] gastamos boa parte do que tínhamos ganhado com muita dificuldade para tentar salvá-lo, estávamos no fundo do poço, mas foi tudo em vão. Ele veio a óbito. Eu estava sozinha com meus filhos, com muita tristeza e com muitos desafios pela frente, dividi com eles o pouco que tinha sobrado. Trabalhei aos domingos, aos feriados e até tarde da noite com meu mercado e loja (História 60).

Esses acontecimentos inesperados acabaram por deixar essas mulheres muito abaladas e as mesmas se viram sem forças para continuar. Porém, passado o susto inicial, tiveram mais garra para enfrentar os problemas que surgiram posteriormente, como a falta do familiar e os problemas financeiros deixados pela doença ou falta daquele que auxiliava na renda da família. Como saída, focaram na empresa e no trabalho, mantendo suas mentes ocupadas e produtivas.

Minha vida pessoal passou por momentos muito difíceis, como a perda da minha filha aos seis anos de idade, o que quase me fez desistir de tudo. Mas o trabalho foi importante para sair do buraco negro que se instalou nas nossas vidas depois desta perda [filha de 6 anos] (História 30). 
Para poder aceitar essa tragédia, entrei no trabalho de uma maneira que nunca imaginei na minha vida, fato esse que surgiu de inspiração para entrar em um outro ramo pioneiro na minha cidade, o aluguel de roupas sociais (História 38).

[...] passamos por um momento muito triste onde ocorreu o falecimento repentino de meu pai. Essa época acho que foi de todas a pior, pois estávamos destruídos psicologicamente e a estrutura da empresa não poderia ficar abalada, pois o sonho tinha que continuar (História 15).

Os problemas financeiros também foram evidenciados, principalmente os relacionados a desequilíbrios de caixa e pela falta de recursos para investir no crescimento da empresa. Os problemas de caixa se dão pela falta de clientela e inadimplência, resultados da falta de maiores cuidados (ou conhecimentos) sobre a gestão financeira. Problemas econômicos também assolaram as empresas que sentiram a instabilidade que trazia incerteza para o mercado, como as mudanças de moeda.

[...] a falta de experiências no ramo que acabou a acarretar alguns erros, a abertura de crédito foi um dos pontos negativos para a empresa, pois não foi feita uma análise correta de abertura de crédito e as coisas começaram a desandar, já que os clientes não tinham limite para compras nem data definida para pagamento. Toda essa situação foi se prolongando, pois o capital de giro ficou todo comprometido no crediário (História 63).

Tanto para o início como na maturação do negócio, muitas empreendedoras se viram sem recursos para financiar as operações da empresa, o chamado capital de giro, assim como para investir no crescimento porque não tinham recursos disponíveis.

Nesta época consegui outro empréstimo junto ao SEBRAE e fizemos uma pequena reforma na confeitaria. Muito trabalho, muito desprendimento e muitas dívidas. Trabalhávamos para manter a empresa viva e não fazíamos quase nada de retiradas, pois haviam os empréstimos, as despesas bancárias mensais que nos sufocavam (História 16).

Outras questões também foram destacadas e que contribuíram para a situação financeira das empreen- dedoras, como assaltos recorrentes. Duas mulheres citaram ter sido avalistas de outras pessoas e acabaram arcando com a dívida e problemas na sociedade, quando sócios que, por desentendimentos, decidiram se retirar da empresa, acarretando despesas extras, em momento financeiro difícil.

[...] arrombaram a loja e levaram tudo que tinha dentro, inclusive os cabides e a cortina do provador. Todos pensavam que tudo tinha acabado, e então vieram as acusações e críticas: - Eu não disse que não iria dar certo?... Sem mercadorias, com os cheques devolvidos e as duplicatas protestadas, como fazer? (História 23).

Por falta de recursos para investir, utilizaram-se da criatividade.

O início foi difícil. Muitas vezes, eu colocava algumas caixas vazias embaixo das pilhas de sapatos para dar a impressão de quantidade. Comprava sempre a quantidade mínima para ter bastante variedade (História 25).

Os problemas foram resolvidos com planejamento, o que ajudou a reverter a situação e a dar continuidade ao negócio. Planejaram, realizaram parcerias e trataram com cuidado os clientes.

[...] conversamos com fornecedores e fizemos parcerias, renegociamos dividas, reestruturamos o crediário, fizemos promoções. A reestruturação do crediário foi o passo mais delicado; optamos por fazer um informativo repassando que estávamos reestruturando e que para isso haveria algumas mudanças, as quais eram: todos os produtos em ofertas e produtos da padaria não seriam vendidos no crediário e sim somente a vista. E o resultado veio, colocamos a terça-feira da fruta e verdura a um preço único (realizado parceria com o fornecedor de verduras); aos poucos os clientes estão se acostumando a comprar a vista. (História 63).

Por fim, as histórias evidenciaram problemas com a gestão. A falta de planejamento e conhecimento sobre o mercado de atuação foi o maior responsável por estas questões.

[...] começamos a trabalhar nas duas casas, foi um caos, pois não tínhamos planejado, faltou pessoal para trabalhar, a distância era grande $e$ a filial dependia completamente da matriz, 
assim nos demos conta que a empresa era eu e o meu marido, ele na parte comercial e eu na financeira. Fizemos um investimento grande, só trabalhamos dois meses, e não deu nem para pagar as mercadorias que foram vendidas ali (História 69).

As maiores dificuldades encontradas no início foram mão de obra qualificada, falta de matéria-prima, devido à especificidade do produto, terceirização de alguns processos da produção (bordado) com empresas não especializadas e falta de um sistema que organizasse a empresa como um todo.

[...] Quanto à mão de obra, ainda sentimos dificuldades de encontrar pessoas especializadas, os colaboradores da produção são incentivados e treinados para se especializarem cada vez mais. A matéria-prima, à medida que fomos expandindo nossa produção, tivemos que buscar tecidos e aviamentos em outros países. O bordado das peças, atualmente, é feito na empresa. (História 37).

Nas histórias analisadas foram verificados relatos de que os erros trouxeram o aprendizado necessário para dar continuidade à empresa. A saída para essas questões veio pela busca de conhecimento e informações sobre o setor de atuação e gestão de empresas. Com um bom planejamento conseguiram melhorar a gestão, prevenir incertezas e definir metas para o futuro. "O maior desafio em ser empreendedora é não estar limitada ao dia a dia do negócio e sim estar inovando e buscando cada vez mais mercado e clientes, atendendo com qualidade e pontualidade" (História 51).

Segmentando os problemas encontrados na gestão do negócio, os relacionados ao mercado estão evidenciados nos relatos. São fatores do ambiente externo e incontroláveis, mas que precisavam ser analisados para prever possíveis consequências negativas no andamento da empresa, como a perda de participação de mercado, entrada de novos concorrentes, mudanças no padrão de consumo, dentre outros fatores.

A verificação de tais questões, o olhar no mercado, levou uma empresa a trocar de setor de atuação: "[...] lembro da entrada dos brinquedos importados que causaram um grande estrago nas indústrias nacionais. As mudanças nos planos econômicos [...]. Diante dessas dificuldades, [...] direcionamos nosso negócio para calçados e confecções" (História 19).
Assim que as empresas entenderam a sazonalidade de seu setor puderam planejar antecipadamente as oscilações de venda ao longo do ano, principalmente na temporada de veraneio. Outras trabalharam melhor o mercado fazendo com que conhecessem e aceitassem seu produto, como o caso da farmácia voltada para o atendimento a clientes diabéticos e a universidade à distância.

Muitas foram as dificuldades encontradas ao implantar esta parceria, sendo a mais forte a falta de credibilidade nesta forma de ensino, uma vez que sempre foi presencial.

No primeiro vestibular conseguimos somente 12 alunos e nem por isso desistimos, pois quando se acredita que o produto é bom, tem legalidade, tem mercado, precisamos persistir tentando todas as possibilidades, só assim seremos vitoriosos dentro do segmento (História 71).

A falta de credibilidade foi também sentida pelas empreendedoras, tanto por acreditarem que não eram capazes de gerir uma empresa, aprender um novo ofício ou realizar uma atividade simples, como pela venda porta a porta sem ter a necessidade financeira para tal. "Muitas pessoas não entendiam a razão de me "sujeitar" àquela atividade (História 24)".

Por ser mulher, muitas portas se abriram e
muitas outras se fecharam! [...] Como ninguém
acreditava muito no projeto tive que fazê-lo so-
zinha e paralelamente às demais atividades do
dia a dia, mas não desisti. (História 86).

Uma das mulheres sofreu preconceitos durante muitos anos até alcançar o sucesso empresarial por ser interiorana, com pouco estudo e passando muitas necessidades financeiras. Ela não só deu a volta por cima, tendo muito sucesso na sua empresa, como ganhou reconhecimento na região, sendo eleita vereadora. "Pelo fato de vir do interior, tinha dificuldades em impor liderança e algumas pessoas não valorizavam o meu trabalho e não concordava com a forma que era conduzida a produção. Fui humilhada muitas vezes" (História 36).

Ainda como problema, levantou-se a ausência de apoio do poder público para poder ampliar a atuação da empresa, dificultando a situação. 


\subsection{Discussão}

O relato das histórias de vida estudadas revelou que além dos problemas inerentes ao empreendedorismo, a condição das mulheres contribui para o aumento das dificuldades durante o processo empreendedor. O preconceito, por exemplo, é sentido por meio da falta de respeito e da credibilidade das pessoas com quem as mulheres se relacionam. Entretanto, apenas parte dessa questão é referente ao fato de serem mulheres, o que corrobora os achados de Porto (2002). Porém, o fato de eles serem jovens contribuiu muito mais para o agravamento da situação.

As maiores dificuldades foram expostas pelas mulheres que atuaram em setores tidos como masculinos e, por isso, vistas de forma diferente por clientes, fornecedores e funcionários, o que impôs restrições nas relações com as empreendedoras. Nesse sentido, este estudo confirma a pesquisa de Botelho et al (2008) que aponta barreiras para as mulheres que desejam atuar em setores que são tradicionalmente masculinos, até mesmo pela baixa presença feminina.

O preconceito da família e dos homens de sua relação também foi verificado por Porto (2002). Entre as catarinenses estudadas, esse fato se deu somente no ambiente empresarial em casos de mulheres que assumiram empresa do pai voltada a setores tradicionalmente masculinos. Esse preconceito pode ser entendido mais como um descrédito, somado ao fato de que quando o empreendimento se deu junto aos maridos esse comportamento não foi percebido nos relatos.

As dificuldades de conciliar múltiplos papéis como mães, esposas e empresárias foi outro problema relatado pelas mulheres. O fato da criação dos filhos estar atrelado à mãe na estrutura familiar é predominante nos relatos das empreendedoras, embora não citem imposição do marido quanto a trabalharem fora ou constituírem suas empresas. Strobino (2009) buscou entender esse conflito vivido pelas empreendedoras, citando a pressão que sentiam dos maridos e filhos, acontecimento não verificado nas histórias de vida das empreendedoras catarinenses. Por outro lado, evidencia-se alta colaboração dos filhos e cônjuges, principalmente nos cuidados com a empresa, contrariando a pesquisa de Porto (2002) e Buttner e Moore (1997). Observou-se nos relatos o fato das famílias serem propensas a aceitar as limitações que o empre- endimento trazia em função do auxílio que ofereciam no dia a dia da empresa.

Strobino (2009) cita como fatores de resolução dos conflitos, o controle das emoções, evitando discussões; o equilíbrio de horários, o compartilhamento com a família as atividades domésticas, a busca de diálogo e o apoio na família. Considerando o relato das empreendedoras catarinenses, o que se verifica é o apoio da família como fator mais recorrente, fato este também encontrado por Powell e Eddleston (2013) que revelaram os benefícios encontrados pelas mulheres na sinergia trabalho-família.

Apesar do apoio da família, entre as mães, foi constatado o sentimento de culpa, confirmando o estudo de Porto (2002), cujo convívio com os filhos foi prejudicado em função da dedicação à empresa. Essa difícil decisão, por fim, é encarada como um sacrifício necessário para garantir o bem estar familiar.

Este trabalho também corroborou o estudo de Mcgowan, Redeker, Cooper e Greenan (2012) em que o prazer advindo do processo empreendedor, resultante da maior liberdade e flexibilidade, é temperado por descontentamento, em função das demandas de tempo entre as necessidades de equilibrar as exigências do negócio e os interesses dos filhos. E, apesar da evidência de que as mulheres dão grande peso $e$ valor a seu trabalho, a família parece permanecer como valor central, estando muito presente nos relatos das empreendedoras catarinenses.

\section{Considerações Finais}

O objetivo geral desta pesquisa consistiu em analisar os problemas encontrados ao longo do processo empreendedor de mulheres, a partir das histórias de vida contadas pelas participantes do Prêmio SEBRAE Mulher de Negócios 2010, em Santa Catarina.

Todas as mulheres pesquisadas tiveram contratempos em suas histórias como empreendedoras. Os principais problemas encontrados ao longo do processo empreendedor foram pessoais e familiares, financeiros, dificuldades de gestão, falta de credibilidade e dificuldades de mercado. 
A conciliação dos múltiplos papéis de mãe, esposa e empreendedora é uma das dificuldades mais destacadas. A gestão financeira se coloca como a segunda dificuldade mais citada, muitas vezes refletindo os problemas gerados pela falta de planejamento prévio. Com as empresas já constituídas aumenta a quantidade de empréstimos bancários para atender aos apuros pelos quais a empresa passa. Porém, não é possível afirmar se há algum tipo de preconceito por parte do mercado para com essas mulheres ou se as empreendedoras optam por não recorrerem a outras fontes de recursos. As empreendedoras relatam o aprendizado relacionado a esta questão ao longo do caminho, ressaltando a importância de conhecer seu ramo de atuação antes de empreender, buscar informações do mercado e elaborar plano de negócios, o que se configura não apenas um problema das mulheres, mas do empreendedorismo de uma forma geral.

Porém, de fato, algumas dificuldades são agravadas por essas empreendedoras serem mulheres, principalmente a falta de credibilidade dos clientes, fornecedores e funcionários nas empresas relacionadas as atividades consideradas masculinas. Preconceitos também foram decorrentes da pouca idade das empreendedoras.

Ao longo do processo, as dificuldades trouxeram aprendizado e mais força para dar continuidade ao negócio, o que ocorreu na forma de acertos e erros e que leva à busca constante do conhecimento.

Pode-se admitir, ainda, que as mulheres empreendedoras catarinenses com diferentes perfis, escolaridades, origens, estrutura familiar, conhecimentos $e$ com empresas constituídas em diferentes setores e em épocas distintas, chegam a uma mesma constatação: ir atrás do sonho de empreender vale a pena. De acordo com as narrativas das empreendedoras, apesar dos problemas enfrentados, as suas jornadas foram marcadas por uma dose de sonho, força de vontade, mas, acima de tudo, de muito trabalho e empenho.

Este trabalho contribui para o avanço teórico dos conhecimentos acerca dos fatores socioculturais e familiares que afetam o empreendedorismo feminino, considerando o contexto empreendedor não como uma variável de controle, mas como parte da história das mulheres, abordagem importante para compreender o fenômeno empreendedor, conforme Zahra e Wright (2011). O trabalho também se apoiou em
Gartner e Birley (2002) que apontam para o fato de que as questões substantivas em empreendedorismo devam ser estudadas por meio de métodos e abordagens qualitativas. Contribuições também são trazidas para a prática, na medida em que podem auxiliar na elaboração de programas educacionais e de suporte as políticas públicas que venham a promover a atividade empreendedora entre as mulheres, já que muitos dos problemas constatados se dão em função da ausência de conhecimento do negócio em que atuam.

Em função de seu caráter qualitativo, o trabalho não se propõe a generalizar os resultados para toda a população de mulheres empreendedoras catarinenses, o que poderia ser considerada uma limitação. Porém, aborda questões substantivas que raramente são consideradas no campo do empreendedorismo, e que só podem ser estudadas por meio de métodos e abordagens qualitativas.

\section{REFERÊNCIAS}

BARBOSA, Felipe Carvalhal; CARVALHO, Camila Fontes de; SIMÕES, Géssica Maria de Matos; TEIXEIRA, Rivanda Meira. Empreendedorismo feminino e estilos de gestão feminina: estudo de casos múltiplos com empreendedoras na cidade de Aracaju-Sergipe. Revista

da Micro e Pequena Empresa, Campo Limpo Paulista, v. 5, n. 2, p.124-141, maio-ago., 2011.

BOTELHO, Louise de Lira Roedel et al. Desafios gerenciais das mulheres empreendedoras: como exercer a liderança em espaços de identidade masculina? O caso da Alpha Tecnologia. 2008.

BRUCE, D. Do husbands matter? Married women entering self-employment. Small Business Economics, vol. 13, pp. 317-29, 1998.

BUTTNER, H.; MOORE, D. Women's organizational exodus to entrepreneurship: self-reported motivations and correlates with success. Journal of Small Business

Management, jan. p. 34-47, 1997.

CHIZZOTTI, Antonio. Pesquisa em ciências humanas

e sociais. 7. ed. São Paulo: Cortez, 2005. 
DAILY, C.M., CERTO, S. T.; DALTON, D. R.

Entrepreneurial ventures as an avenue to the top? Assessing the advancement of female CEOs and directors in the Inc.100. Journal of Developmental Entrepreneurship, USA, v. 4, n. 1, p. 19-32, 1999.

DOLABELA, Fernando. O segredo de Luísa: uma ideia, uma paixão e um plano de negócios: como nasce o empreendedor e se cria uma empresa. 13. ed. São Paulo: Cultura, 2006.

FLICK, Uwe. Desenho da pesquisa qualitativa. Porto Alegre: Artmed, 2009.

GARTNER, W. B.: BIRLEY, S. Introduction to the special issue on qualitative methods in entrepreneurship research. Journal of Business Venturing, v. 17, p. 387-395, 2002.

GEM - Global Entrepreneurship Monitor.

Empreendedorismo no Brasil - 2009: relatório nacional. Curitiba: IBQP, 2010.

\section{GEM - GLOBAL ENTREPRENEURSHIP MONITOR.}

Empreendedorismo no Brasil - 2012: relatório executivo. Curitiba: IBQP, 2012.

GOMES, A. F. O perfil empreendedor de mulheres que conduzem seu próprio negócio: um estudo na cidade de Vitória da Conquista, BA. Revista Alcance, v. 11, n. 2, p. 207-226, 2004.

Jonathan, Eva G. Empreendedorismo feminino no setor tecnológico brasileiro: dificuldades e tendências. In:

EGEPE - ENCONTRO DE EMPREENDEDORISMO E GESTÃO DE PEQUENAS EMPRESAS, 3., 2003, Brasília, DF. Anais... Brasília, DF, UEM/UEL/UnB, 2003.

LOCKYER, J.; GEORGE, S. What women want: barriers to female entrepreneurship in the West Midlands. International Journal of Gender and Entrepreneurship, USA, v. 4, n. 2, p.179-195, 2012.

MACHADO, H. V. et al. O processo de criação de empresas por mulheres. RAE eletrônica, [on-line], v. 2, n. 2, 2003.

\section{MACHADO, Hilka V. Identidade empreendedora}

de mulheres no Paraná. Florianópolis, 2002. Tese (Doutorado) - Universidade Federal de Santa Catarina, Centro Tecnológico. Programa de Pós-Graduação em Engenharia de Produção, 2002.

MARLOW, S. Self employed women: New opportunities, old challenges. Entrepreneurship \& Regional

Development, USA, v. 9, n. 3, p. 199-210, 1997.

MCGOWANA, P. et al. Female entrepreneurship and the management of business and domestic roles: Motivations, expectations and realities. Entrepreneurship \&

Regional Development, USA, v. 24, n. 1-2, p. 53-72, 2012.

NOGUERA, M.; ALVAREZ, C.; URBANO, D. Sociocultural factors and female entrepreneurship. Spriger Science+Business Media New York, USA, 2013.

PORTO, Maria de Fátima Silva. Com licença, eu vou à luta: mulheres empresárias de patos de minas - 1980-90. Uberlândia, 2002. 250 f. Tese (Mestrado) - Universidade Federal de Uberlândia. Programa de Pós-graduação em História. Uberlândia, 2002.

PORTO, Maria de Fátima Silva. De batom e salto alto: experiências de emancipação de mulheres empresárias de Patos de Minas, 1980-1990. São Paulo: ANNABLUME, 2002.

POWELL, Gary N.; EDDLESTON, K. A. Lonking familyto-business enrichment and support to entrepreneurial success: do female and male entrepreneurs experience different outcomes? Journal of Business Venturing, USA, v. 28, n. 2, 2013.

RICHARDSON, Roberto Jarry e colaboradores. Pesquisa social: métodos e técnicas. 2. ed. São Paulo: Atlas, 1989.

SEBRAE. Anuário do trabalho na micro e pequena empresa. Brasília, DF: DIEESE, 2006.

SCHINDEHUTTE, M.; MORRIS, M.; BRENNAN, C.

Entrepreneurs and motherhood: Impacts on their children in South Africa and the United States. Journal of Small Business Management, USA, v. 41, n. 1, p. 94-107, 2003. 
Graziela Dias Alperstedt • Juliane Borges Ferreira • Maurício Custódio Serafim

STROBINO, Márcia Regina de Campos; TEIXEIRA,

Rivanda Meira. O Empreendedorismo feminino

e o conflito trabalho-família: estudo de caso

no setor da construção civil da cidade de Curitiba.

Empreendedorismo e Estratégia de Empresas de Pequeno

Porte - 3Es2Ps. Curitiba: 2010.

TOURAINE, Alain. O mundo das mulheres. Tradução

de Francisco Moras. Petrópolis: Editora Vozes, 2007.

WINN, J. Entrepreneurship: not an easy path to top management for women. Women in Management

Review, USA, n.19, n. 3, p. 143-153, 2004.

ZAHA, S. A.; WRITH, M. Entrepreneurship's Next Act.

Academy of Management Perspectives, USA,

November 2011. 